\title{
One of these things is not like the others: Patients with multiple primary lung cancers
}

\author{
Victor van Berkel, MD, PhD \\ From the Department of Cardiovascular and Thoracic Surgery, University of Louisville School of Medicine, \\ Louisville, Ky. \\ Disclosures: Author has nothing to disclose with regard to commercial support. \\ Received for publication Aug 24, 2017; accepted for publication Aug 26, 2017; available ahead of print Sept 19, \\ 2017. \\ Address for reprints: Victor van Berkel, MD, PhD, 201 Abraham Flexner Way, Suite 1200, Louisville, KY 40202 \\ (E-mail: victor.vanberkel@louisville.edu). \\ J Thorac Cardiovasc Surg 2018;155:380-1 \\ $0022-5223 / \$ 36.00$ \\ Copyright (c) 2017 by The American Association for Thoracic Surgery \\ http://dx.doi.org/10.1016/j.jtcvs.2017.08.074
}

The presentation of a patient with more than one pulmonary nodule, in the absence of other obvious disease, has presented a dilemma to clinicians and researchers for several decades. The American Joint Committee on Cancer staging system for lung cancer paints a grim picture for patients with multiple pulmonary nodules, describing patients with multiple nodules in a single lobe as having $\mathrm{T} 3$ disease, a patient with a nodule in an ipsilateral separate lobe as having $\mathrm{T} 4$ disease, and a patient with a contralateral nodule as having M1a disease. ${ }^{1}$ Intrinsic to these staging criteria is the assumption that these disparate nodules are metastatic deposits from a single primary tumor. Although this is possible, it is also possible for any given patient that separate nodules represent metachronous, rather than metastatic lesions-and that the patient has 2 separate T1 lesions, rather than a single T3 or M1 lesion. Those possibilities obviously have very different long-term outlooks; unfortunately, it is often impossible to determine which possibility is being manifested purely on the basis of radiographic criteria.

The clinical and pathologic criteria for establishing the presence of multiple primary lung cancers were initially "commonsense" criteria described by Martini and Melamed $^{2}$ in 1975. Tumors were considered metachronous if they were of different histologic types, or if they were anatomically separated without evidence of intervening nodal disease or other distant disease. These criteria were established when there were far fewer tools at our disposal for the differentiation of tumors of similar histologic types. As our knowledge of the various genetic mutations responidentify the mutations within specific tumor nodules has improved, and we are now able to assess more accurately whether separate nodules represent genetically identical specimens or truly distinct growths.

In this issue of the Journal, Chen and colleagues ${ }^{4}$ present a single-institution review of 96 patients in 7 years who underwent surgical excision of multiple pulmonary nodules sible for malignant transformation has grown, our ability to

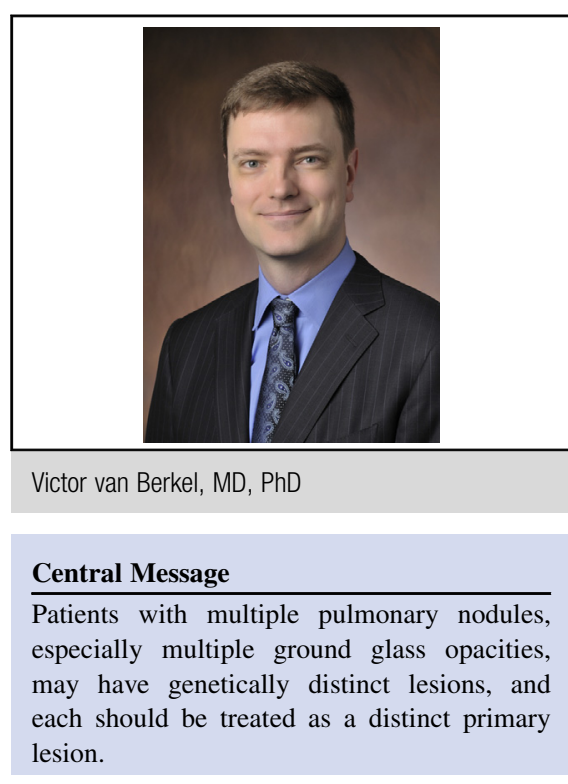

See Article page 371 . and met the clinical and pathologic criteria for metachronous lesions. They broke these patients into 3 groups according to the radiographic appearance of the lesions (multiple ground glass opacities, 1 ground glass lesion and 1 solid lesion, or multiple solid lesions) and examined their survivals. In this admittedly small sample, they found that patients with ground glass opacities did substantially better than did those with multiple solid tumors, a finding that recapitulates the findings of other groups. ${ }^{5,6}$

They then examined a subset of these patients for genetic mutations to determine the true rate of metastatic versus metachronous disease. These data demonstrated a very high rate of the presence of different mutations in different tumors (discordance rate of $94 \%$ when mutations were identified), reinforcing the presumption that these tumors represented separate instances of disease. It is worth noting, however, that only 39 patients underwent mutational analysis, and only $75 \%$ of the tumors evaluated had a mutation identified.

Although the article of Chen and colleagues ${ }^{4}$ suffers from evaluating a relatively small and heterogeneous population, it represents a unique amalgamation of radiographic, clinical, and genomic information that provides new support for the established criteria for diagnosing multiple primary lesions, rather than metastatic disease. As such, this article suggests that an aggressive surgical 
stance when treating patients with multiple isolated pulmonary nodules, especially multiple ground glass opacities, is warranted.

\section{References}

1. Edge SB, Compton CC. The American Joint Committee on Cancer: the 7th edition of the AJCC cancer staging manual and the future of TNM. Ann Surg Oncol. 2010; $17: 1471-4$.

2. Martini N, Melamed MR. Multiple primary lung cancers. J Thorac Cardiovasc Surg. 1975;70:606-12.
3. Liu Y, Zhang J, Li L, Yin G, Zhang J, Zheng S, et al. Genomic heterogeneity of multiple synchronous lung cancer. Nat Commun. 2016;7:13200.

4. Chen K, et al. Favorable prognosis and high discrepancy of genetic features in surgical patients with multiple primary lung cancers. J Thorac Cardiovasc Surg. 2018;155:371-9.

5. Shimada Y, Saji H, Otani K, Maehara S, Maeda J, Yoshida K, et al. Survival of a surgical series of lung cancer patients with synchronous multiple ground-glass opacities, and the management of their residual lesions. Lung Cancer. 2015;88: 174-80.

6. Shrager JB. Approach to the patient with multiple lung nodules. Thorac Surg Clin. 2013;23:257-66. 